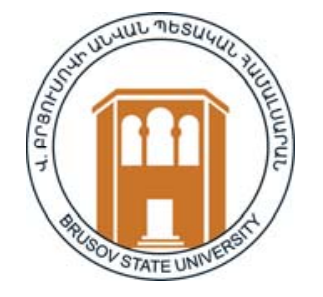

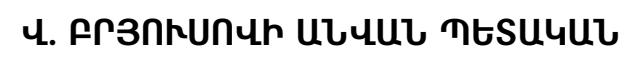
CUUULUURUL

ГОСУДАРСТВЕННЫЙ УНИВЕРСИТЕТ

ИМЕНИ В. БРЮСОВА

BRUSOV STATE UNIVERSITY

คulคtr

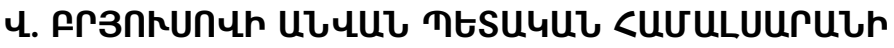
ВЕСТНИК ГОСУДАРСТВЕННОГО УНИВЕРСИТЕТА ИМЕНИ

B. БРЮСОВА

BULLETIN OF BRUSOV STATE UNIVERSITY

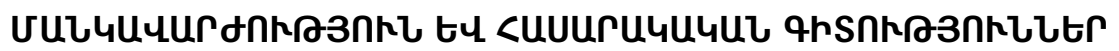

ПЕДАГОГИКА И СОЦИАЛЬНЫЕ НАУКИ

PEDAGOGY AND SOCIAL SCIENCES

2(55)

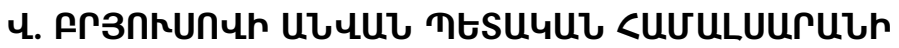

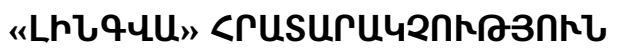

เГヒบuし - 2021 
<S? 330.001(479.25)+330.001(478.9)

DOI: 10.51307/182931072015233260/21.2-196

\section{SMART SPECIALIZATION AS AN INCENTIVE FOR THE DEVELOPMENT OF CREATIVE ECONOMIES IN ARMENIA AND MOLDOVA}

\section{ROBERT KHACHATRYAN, ELENA SIMCIUC}

Keywords: SMART specialization, creative economy, creative assets, education innovations, educational programs

Conditioned by current research and technological achievements, economic systems have undergone a range of structural transformations. Respectively, the targeted state policies in SMART specializations and investments in the processes of producing creative assets have served as a basis for the emergence of creative economies. These new advancements have also created new challenges for universities. In competitive economies universities have undertaken the missions of innovating and incorporating solutions into the educational processes by preparing professionals who will possess competitive knowledge and skills. The aim of the article is to conceptualize the focal role of SMART specializations in the successful development of creative economies in Armenia and Moldova. It is also justified that the development of targeted policies in SMART specializations at the state level and creating the competitive environment for effective execution of those policies at institutional levels of universities will create further guarantees for competitive societies in the knowledge economies. Science and research, as well as innovative technologies, have always been the driving force of the economy. Aiming to provide people with a higher standard of living and living conditions, science and research achievements and innovative technologies have led to systemic and structural transformations of the economy. The introduction of science and research assets and innovative technologies into the economy has led to the emergence of knowledge economies.

The knowledge economy equally refers to the knowledge-intensive activities of production and services that contribute to an accelerated pace of technical and scientific advance of the given society. A knowledge economy can be characterized as a system of consumption and production that is based on intellectual capital. Intellectual capital assumes the following:

- it is a significant part of a company's value, consisting of intangible assets, such as the value of its workers' knowledge. 
- it has a greater reliance on intellectual capabilities than on physical inputs or natural resources.

Touching upon the concept of knowledge economy, it is possible to come across the idea of the creative economy having intellectual property and creativity as highlights. The creative economy introduces the latest developments and growing interest as a post-industrial urban revitalization strategy (Stern and Seifert 2008). Scientists and theorists came up with a new object of study conditioned by a growing interest in creative cities and cultural industries. However, there are different approaches to the term in different sources without distinctly defining it and without transparency in the application of data and statistics (Markusen et al. 2008).

The study of the term and its wide circulation in the professional literature is conditioned by the fact that the creative industries have seized the attention of city- and region-focused policy-makers, managers, and academics (Kemeny et al. 2019:1). The concept of the creative economy has arisen to highlight the importance of creativity as a power in contemporary economic systems. The concept of creative economy was first originated in industrialized countries but its impact has then expanded all over the world. Though the concept is in the spotlight of scientists and theorists it is still subject to endless debates among them. It is suggested that a creative economy brings new perspectives to urban development. In contrast, there is a point that the policy that is based on a creative economy secures advantages only to the middle classes, which, in turn, leads to social exclusion (Peck 2005). The term of creative economy was first introduced in 2001 by John Howkins (Howkins 2001: 8) as "the transactions of creative products that have an economic good or service that results from creativity and has economic value."

Creative economy is a comprehensive concept that encompasses cultural goods and services, as well as toys and games and the whole area of R\&D (research and development). Hence, while identifying cultural actions and processes as the essence of a compelling modern economy, it is also involved with manifestations of creativity in areas that would not be interpreted as cultural ones (UNESCO, UNDP 2013: 20). Creative economy stands to present creativity throughout the entire economy (OECD 2005, Howkins 2001, Markusen 2008). The concept of creative economy was defined as a developing concept which is based on creative assets leading to economic growth and development (United Nations Conference on Trade and Development (UNCTAD 2010). The creative economy has the following characteristics (UNCTAD 2010):

- promoting income generation, job creation, and export profits while advancing social inclusion, cultural variety, and human development; 
- comprising economic, cultural, and social features communicating with technology, intellectual property, and tourism purposes;

- including a set of knowledge-based economic actions with a development dimension and cross-cutting linkages at macro and micro levels to the whole economy;

- emphasizing achievable development opportunities for innovation, multidisciplinary policy replies, and inter-ministerial action;

- being based on creative industries.

Summing up the mentioned definitions and characteristics, it is possible to suggest an overall definition of the term, that is, the creative economy is an economic model based on creative assets, intellectual property, individual skills, and talent, as well as innovation, which supplies goods and services to the society having economic value and leading to economic growth and development. Based on intellectual capital and creativity, creative economy emphasizes the significance and added value of culture and creativity in the national economy. To supply the mentioned assets to the economy, higher education institutions need to transform the educational programs to effectively address the changing conditions of the external environment. In the process of educational transformations, higher education institutions have faced a new concept - SMART specialization.

In the context of economic transformation, SMART specialization is of key importance. SMART specialization, as an innovative educational program addressing economic change, helps higher education institutions to provide specialists who have the knowledge, skills, and capabilities in accordance with the requirements of the labor market and who are capable to solve sectoral problems. It should be mentioned that higher education institutions contribute to the development of the creative economy through the training of skilled professionals through smart specialization. SMART specialization intends to apply knowledge assets, intellectual capital, and innovation investments to ensure sustainable economic growth. The concept of SMART specialization meets with the idea of a knowledge-based economy that utilizes knowledge assets, high technologies, and human resources at all to secure economic growth and development. SMART specialization can be counted as an essential element of a knowledge-based economy (Khachatryan and Simciuc 2020: 195).

SMART specialization comes to change the traditional forms of literacy, conditioned by digital media and new communication technologies impacting interactions and literacy skills. It should be mentioned that shifts in literacy applications arrive synonymous with the installation of new digital technologies (Underwood, Farrington-Flint 2015: 68). SMART specialization shapes literacy skills in innovative ways. It suggests a new term for literacy- digital literacy, which 
enables individuals to deviate from traditional forms of literacy and identify a broader set of skills involving obtaining and assessing information within a multimodal environment. Within recent years the term digital literacy has been examined, explained, and embraced by many academics and scientists heading to extensive descriptions of digital literacy, visual literacy, television literacy, and, within many higher education institutions, information literacy. However, the term digital literacy encompasses much more than just the functional element of learning; it includes a new set of skills and competencies focused on obtaining information, assessing sources, and interpreting written and visual illustrations.

SMART specialization enables individuals to develop knowledge and skills necessary to be literate in the $21^{\text {st }}$ century world. One of the crucial aspects of digital literacy is the ability to function within a multimodal environment (Underwood, Farrington-Flint 2015: 67-70). Abilities that digital literacy aids to develop can highly contribute to the process of applying one's knowledge and skills in the labor market. As Ainsworth suggested (Ainsworth 2008: 191) among such abilities, learning complicated scientific concepts, interacting with multiple forms of representation such as diagrams, graphs, and equations should be specified. That is, with the implementation of digital literacy, SMART specialization ensures the preparation and supply of human capital. Besides provision of human capital through digital literacy, SMART specialization also contributes to the creation of social capital with the help of development of social skills and competences.

Social capital is the gain obtained from an individual's position in a social network, both in regard to the amount and nature of the links and resources that those links themselves own. A feature typical of all kinds of capital (social, financial, human/intellectual) suggests that they are convertible to another kind of capital (Underwood, Farrington-Flint 2015: 80).

The Joint Research Centre of the European Commission suggests the following features for SMART specialization.

Figure 1: Main Areas of SMART Specialization

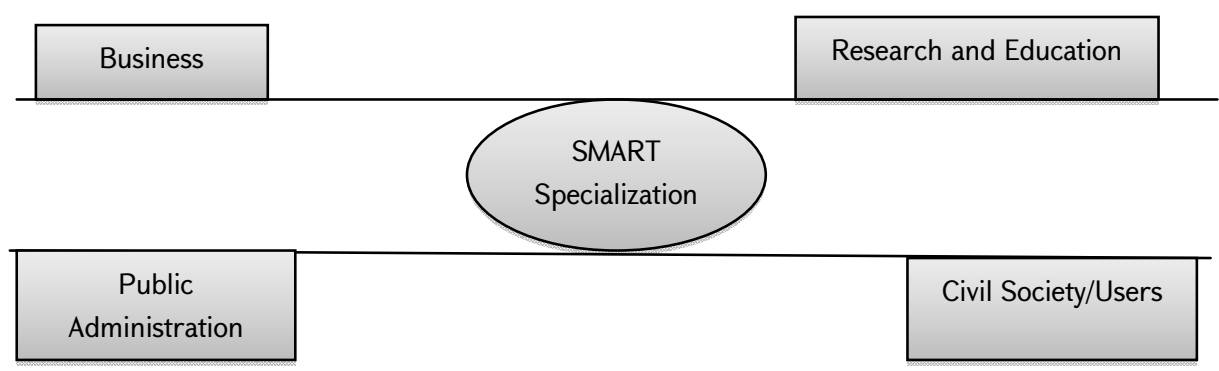


The main areas of SMART specialization encompass the following (Joint Research Centre of European Commission):

- Business: manufacturing and services; primary sectors; financial sector; creative industries; enterprises, both small, medium, and large; clusters and organizations.

- Research and Education: public and private research bodies; universities; education and training; VET centers; science and technology parks; technology transfer offices.

- Public Administration: different government levels; energy and innovation agencies; regional development agencies; business advice offices; public procurement departments; public incubators.

- Civil Society/ Users: non-governmental organizations; citizens' initiatives; societal challenges; cooperative innovative solutions; consumers associations; talents.

SMART specialization serves as an effective basis for the following improvements: evolution of a strategic method to innovation; prioritization of R\&l investments; division of silos (European Commission 2019). Taking into consideration the characteristics and main features of SMART specialization, it can be viewed as an innovative approach aiming at educational reforms. The implementation of SMART specialization within the Armenian context will provide the following advantages: addressing economic transformations; ensuring educational reforms; securing the availability of specialists in accordance with the needs of the labor market; integrating into the European Research Area.

It has proved long ago that innovation plays a crucial role in bringing economic growth and development and in the process of economic transformations. Innovation assumes deviating from the current processes and procedures to create a new concept that makes it possible to approach the work from another perspective (Serdyukov 2017). Innovation is considered as a new thing or a new method of doing something. Innovation brings benefits to all economic activity. It helps to create new products with the new quality and decrease costs of production. It is also possible for innovations to catalyze the processes and procedures and save time (Kogabayev and Maziliauskas 2017: 70). Following the ideas above, innovation is the introduction of something new, a new method of approaching the work that benefits all kinds of economic activity and brings transformation to the previous processes and procedures. Highly appreciating the role of innovations in the process of economic transformations, it should be considered in relation to educational programs that are viewed as providers of innovation to the economy. Such interconnection between concepts necessitates the urgency to touch upon a new term, that is, innovation in education. 
The concept of innovation in education has become widespread in academic circles. OECD (2016) highlighted that innovation in education is crucial from the perspective of bringing improvement in education. It can help to improve the efficiency, as well as outcomes in learning quality and equity of a nation. Innovation in education can come to address the core problems of education which, according to the same source, are productivity and efficiency. Efficiency of education, in turn, is measured by the employment of the gap of capital spent and results in student success and equity (OECD 2016). OECD (2016) considered innovation in education as the investment of an advanced or a new process, products, services, new approaches of managing activities, or new marketing approaches. Though, a few scientists and scholars in education insist that the definition mentioned cannot precisely introduce innovation in education. As presented by Mykhailyshyn et al. (2018), the definition of educational innovation is different from innovations in education as innovation in education has a broader definition compared to that of educational innovation. The definition of innovation in education includes innovations applying to a range of fields, among them educational, social, scientific and technological, economics, administrative fields, etc. Scientific and technological innovation is an outcome of the R\&D of intellectual property for the purposes of implementation and employment, while social innovation includes the process of addressing the social needs of students and teaching staff. On the contrary, educational innovation can be well described as the methods, processes, or procedures in the educational activities that are different from the previous practices, and the objective of which is to enhance educational efficiency in a competitive environment. Educational innovation comprises scientific and methodological, technological, or pedagogical innovation. Though, it should be mentioned that innovation cannot be viewed simply as an invention (Smith and Fund 2009). Moreover, it seems to be a cycle that comprises a range of phases and the collaboration of many stakeholders. Most scholars agree with the idea that a mandatory feature of innovation is the contribution to improvement (Mykhailyshyn et al. 2018, Serdyukov 2017, Smith and Fund 2009, Ng 2009). As Smith and Fund (2009) define, innovation in education it is an innovative product, fresh process, new ideas that are modifying the methodologies based on which people observe a problem or issue by redefining understanding of what is probable, and innovation at the platform level. Assuming that innovation is an issue of an innovative or significantly enhanced output or process, a new marketing technique or a new organizational approach innovation in education can be welldefined as institutions (e.g. schools, universities, training centers) providing the following products and services: presentation of innovative products and services, such as new programs, textbooks, or educational 
resources; implementation of fresh processes for performing their services, such as e-learning services; adoption of new methods of planning their exercises, for instance, interacting with students and parents through digital technologies, performing new marketing methods, such as differential pricing of postgraduate courses (Vincent-Lancrin et al. 2017: 7).

The new practices and procedures mentioned above are viewed as intended improvements (Vincent-Lancrin et al. 2017: 7). Innovation in education can be determined as new ways of developing alternatives to secure a behavioral change in individual people and societies if the current technique does not provide efficiency (Findikoğlu and İlhan 2016). Innovations in education can be characterized as innovative, inventive concepts which are to provide the educational sector with effectiveness and change (Udu 2018: 24).

Assuming an overall definition for the innovation of education, that is, a set of processes and procedures that are intended to secure efficiency and productivity in the educational process as well as ensure the improvement of the education, the role of the higher educational institutions in bringing innovation in education should be highlighted. Higher education institutions have long played a significant role in research, development, technology generation, as well as regional development. From the research outcomes and empirical analysis, it can be concluded that higher education institutions offer an innovative engine of economic development (Florida et al. 2006: 2-3). Etzkowitz and other scholars (Etzkowitz et al. 2000) came up with the idea that the traditional model of a higher education institution, the main missions of which are research and teaching, has been superseded by a frequently "entrepreneurial university" which creates profits and improves its political viability through a technology change, the commercial shift of innovation, the creation of spinoff organizations, and immediate commitment in regional development. Higher education institutions playing a crucial role in contributing innovation to education have had a new commitment to innovating educational programs to address the transformations of the economic and educational environments as well as the needs of the labor market and other stakeholders.

The onset of the information age and the knowledge-based economy necessitates countries to become learning societies. The education of the population and the shilling of the workforce are the factors that are going to determine a nation's fortune in the $21^{\text {st }}$ century much more than they have in the $20^{\text {th }}$ century. The skills base of a nation and the speed with which skilling can adjust to meet new requirements will be as important in determining economic success as a nation's natural resources and financial capital base. These changes will not be achieved without further significant reform in the education and training system. 
The exploitation of the skills, products, and services of creative industries has become a significant competitiveness factor for Armenia, which also seeks to develop the networking possibilities, internationalization, and competitiveness of actors in the creative industries. The situation due to the Coronavirus and the war in 2020 stimulated the consolidation of knowledge and mental capital in the Republic of Armenia. Thus, there was a need to stimulate the development of mind creative thinking and national human capital. For Armenia, it has become a new imperative to seek the application of science and education as a solution to the problem. At the same time, it should be noted that Smart specialization is a part of the National Programme 2020-2023 for the Republic of Moldova on the Research and Innovation. Finally, development of human capital and its creative thinking, research and innovation became the most important strategic priorities for the above mentioned period of time. National Programme 2020-2023 for the Republic of Moldova on the Research and Innovation also point out that knowledge is a more valuable resource in the economy than land, labor, or capital. Increasing the productivity of intellectual labor is a contribution to the development of not only individual companies, it is a contribution to the development of the world economy, a contribution to the development of country. In connection with the transition to a new model of society, higher education takes a particularly important role.

To effectively use the assets of science and education in the economy and implement educational reforms, Armenia needs to implement a complex of activities to address new challenges in the external environment. For this purpose, the experience of Lithuania in establishing and developing valleys of science, studies, and business in 2007 should be taken into consideration as one of the best practices of integration of innovation into science and education. For Armenia, it is advisory to follow the best practices and processes of the fellow countries and develop the concept of valleys and map the stakeholders so that they aim at business integration into science. Valleys can be best characterized as a hub of expertise and a global center for technology, innovation, and social media. According to the Resolution No 308 of the Republic of Lithuania, the concept of the valley is defined as research, studies, and knowledge-intensive business potential of all objects combined in one area with shared or interconnected infrastructure and contributing consistently to the construction of knowledge society and knowledge economy and the improvement of competitiveness of the economy. Following the notions of the concept of the valley, it is probable to suggest an overall definition of it, that is, the valley is a concentration of institutions involved in the fields of education, science, research, innovation, and technologies in one are aiming to contribute to the improvement of the quality of education, invest research outcomes in the 
economy thus securing growth and development of the creative knowledge-based economy. Valley is an integrated concept with three basics: science-research excellence, study-recruiting talent and retaining international capita, business center-business integration.

The development of research valleys as a center for science, research, technology, innovation, and social media aims to improve the quality of education and research, as well as to put them at the core of the economy. The development of valleys would provide the following advantages: ecosystem for educators; creation of modern R\&D centers; increase science-business cooperation; talent attractive; research excellence; international competitiveness.

In order to effectively implement educational reforms and secure significant outcomes, it is compulsory to have strong cooperation between the state and higher education institutions. As across the countries in Europe, in Armenia as well there is a weak cooperation network between the state and universities. Both in European countries and Armenia current R\&D and innovation policies do not address the needs of the business and scientific sector as well. The lack of cooperation between the state and universities leads to a low level of transparency, lack of assessment procedures (Aralica et al. 2017). The main weaknesses of the lack of cooperation between the state and higher education institutions are insufficient funding; the absence of feedback; inadequate management; inadequate designs of tools; weak local connection of tools. However, the strong and effective cooperation between the state and higher education institutions will help to overcome financial and political constraints (Aralica et al. 2017). To succeed in pursuing this goal, the state must be involved in the creation of an institutional policy of integration to ensure structural reforms and address low institutional capacities (Radosevic 2019).

Like other European countries with weak cooperative links between the state and higher education institutions, for Armenia it is of key importance to develop strong cooperation between state bodies and higher education institutions which will guide the development of an institutional policy of integration innovation into science and education. To effectively achieve this goal, the Government of Armenia should sign memoranda with some of the world's competitive educational hubs and think-tanks, such as universities, labs, and different incubators including those of the Silicon Valley. The introduction of SMART specialization can make a significant contribution to the success of this goal as well which will promote the gradual integration of Armenia into the European Research Area.

Following the aim of creating an overall science, studies and business area contributing to the improvement of science and research in Armenia, as well as to the growth and development of the economy the development of valleys as a 
driving force of improved education, science, and creative knowledge-based economy should be considered. The valleys in Armenia would include the following institutions: state universities; Research Centers/ State R\&D institutes; Parks/Science and Technology Parks; businesses; Open Access Centers.

Highlighting the importance and necessity of value development, in Armenia, it would encompass the following fields: agrobiotechnology; biosciences and biotechnology; bioenergy and recycling; forestry; food technologies; molecular medicine; biopharmacy; ICT (Information and communications technology)-Civil engineering; energy; digital service; healthcare; food; environment. As valleys encompass fields of science, studies, and business and contribute not only to education, research, and science but entrepreneurship as well, the role of entrepreneurial education should be emphasized.

Entrepreneurial education has rapidly developed in the last two decades and has contributed to the growth of entrepreneurial society and subsequent knowledge base. Entrepreneurial education is not just about providing people with the knowledge, skills, and capabilities necessary to perform the entrepreneurial activity but also about creating the entrepreneurial mindset as a premise of promotion of the entrepreneurial activity. Entrepreneurial mindset drives the behavior of entrepreneurs to succeed in the $21^{\text {st }}$ century's knowledgebased economy.

Economic transformations, which are conditioned by the introduction of science, research assets, and the latest technologies in the economy, have led to the emergence of a knowledge-based economy. The emphasis on knowledgebased economy, intellectual property, human capital, innovation, and creativity has guided the formation of a creative economy. Economic transformations have presented a number of imperatives to a number of sectors of the economy, including the education sector, which has led to the need to reform educational programs.

As a conclusion, SMART specialization, as an innovative educational program, aims to address the challenges higher education institutions face conditioned by economic transformation. SMART specialization is a powerful investment in the creative economy by providing professionals with knowledge and skills relevant to the economy. Highlighting the importance of science, research, human assets, and innovative technologies for the development of a creative economy, it should be mentioned that reforms of educational programs and the creation of R\&D funds can be a key contribution to ensure economic growth and development. 


\section{REFERENCES}

1. Ainsworth, S. 2008. The Educational Value of Multiple-Representations When Learning Complex Scientific Concepts. In J. Gilbert, M. Reiner \& M. B. Nakhleh (eds.), Visualization: Theory and Practice in Science Education. New York: Springer. 191-208.

2. Amending Resolution No 321 of the Government of the Republic of Lithuania of 21 March 2007 Approving the Concept of the Establishment and Development of Integrated Science, Studies and Business Centers (Valleys), Resolution No 308 of the Republic of Lithuania, 1 April 2014, Vilnius.

3. Aralica, Z., Radosevic, S., Raos, J. 2017. Assessing Research and Policy Support Needs for Innovation in the South East Europe.

4. Etzkowitz, H., Webster, A., Gebhardt, C., Terra, B. 2000. The Future of the University and the University of the Future: Evolution of Ivory Tower to Entrepreneurial Paradigm. Research Policy 29, 313-330.

5. European Commission. 2019. Cohesion Policy and Smart Specialisation in the EU: Achievements, Challenges, Perspectives. DG Regional and Urban Policy.

6. Findikoğlu, F., İlhan, D. 2016. Realization of a Desired Future. Innovation in Education. Universal Journal of Educational Research 4(11): 2574-2580.

7. Florida, R., Gates, G., Knudsen, B., Stolarick, K. 2006. The University and the Creative Economy.

8. Howkins, J. 2001. The Creative Economy: How People Make Money From Ideas. London, UK: Penguin.

9. Joint Research Centre of European Commission. The European Commission's Science and Knowledge Service.

10. Kemeny, T., Nathan, M., O’Brien, D. 2019. Creative Differences? Measuring Creative Economy Employment in the United States and the UK. Regional Studies.

11. Khachatryan, R., Simciuc, E. 2020. SMART Specialization as a Premise for Knowledge-Based Economy. Bulletin of Brusov State University 2(53). Lingva. Yerevan.

12. Kogabayev, T., Maziliauskas, A. 2017. The Definition and Classification of Innovation. HOLISTICA Journal of Business and Public Administration 8(1). pp. 59-72 DOI:10.1515/hjbpa-2017-0005

13. Markusen, A., Wassall, G. H., DeNatale, D., Cohen, R. 2008. Defining the Creative Economy: Industry and Occupational Approaches. Economic Development Quarterly. Sage. 
14. Mykhailyshyn, H., Kondur, O., Serman, L. 2018. Innovation of Education and Educational Innovations in Conditions of Modern Higher Education Institution. Journal of Vasyl Stefanyk Precarpathian National University, 5(1), 9-16.

15. Ng, P. T. 2009. Innovation in Education: Some Observations and Questions. International Journal of Innovation in Education. 1 (1), 8-11.

16. OECD 2005. The Measurement of Scientific and Technological Activities: Guidelines for Collecting and Interpreting Innovation Data: Oslo Manual, 3rd Ed.; Working Party of National Experts on Scientific and Technology Indicators: Paris, France.

17. OECD 2016. Innovating Education and Educating for Innovation: The Power of Digital Technologies and Skills. OECD Publishing, Paris.

18. Peck, J. 2005. Struggling with the Creative Class. International Journal of Urban and Regional Research 29(4): 740-770.

19. Radosevic, S. 2019. Supporting Smart Specialization Strategies and Technology Transfer in South-East Europe. Romanian EU Presidency Conference. Bucharest.

20. Serdyukov, P. 2017. Innovation in Education: What Works, What Doesn't, and What to Do About It? Journal of Research in Innovative Teaching \& Learning. 10 (1), 4-33. https://doi.org/10.1108/JRIT-10-2016-0007

21. Smith, K., Fund, N. V. 2009. Innovation in Public Education: Problems and Opportunities. San Francisco, CA: New Schools Venture Fund.

22. Stern, M. J., Seifert, S. C. 2008. From Creative Economy to Creative Society. Culture and Community Revitalization: A Collaboration. 6.

23. Udu, D. A. 2018. Innovative Practices in Science Education: A Panacea for Improving Secondary School Students' Academic Achievement in Science Subjects in Nigeria. Global Journal of Educational Research, Vol. 17.

24. UNCTAD 2010. Creative Economy: A Feasible Development Option.

25. Underwood, J. D. M., Farrington-Flint, L. 2015. Learning and the EGeneration. WILEY Blackwell.

26. UNESCO, UNDP 2013. Creative Economy Report: Widening Local Development Pathways. Special Edition. France.

27. Vincent-Lancrin, S., Jacotin, G., Urgel, J., Kar, S., González-Sancho, C. 2017. Measuring Innovation in Education: A Journey to the Future, OECD Publishing: Centre for Educational Research and Innovation, Paris. 


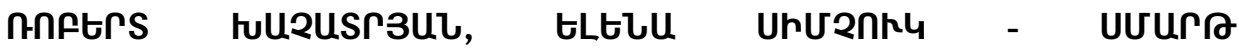

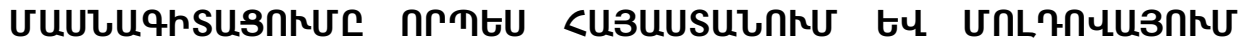

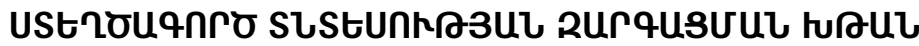

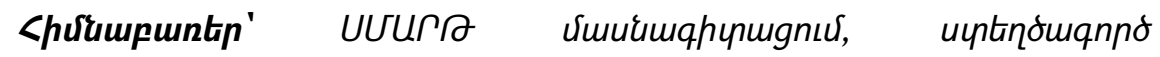

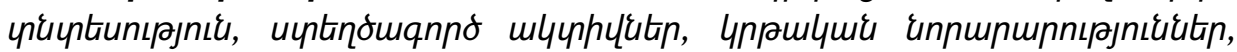
цnрulquí snuqntin

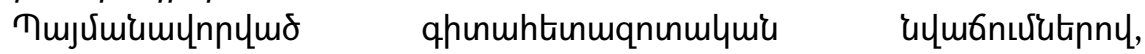

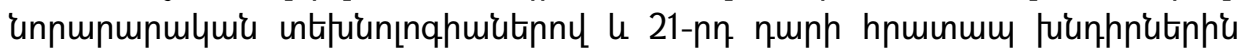

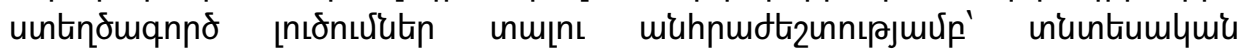

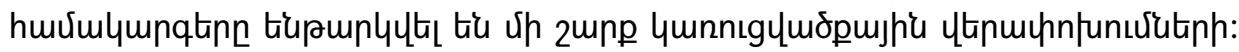

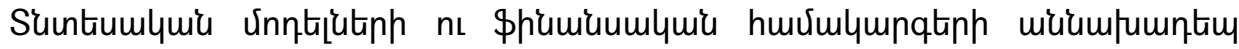

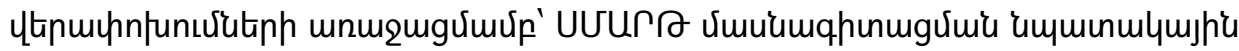

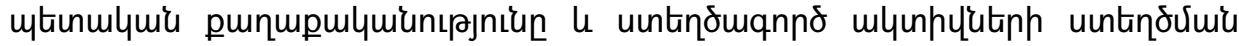

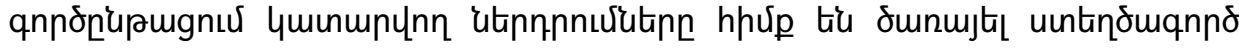

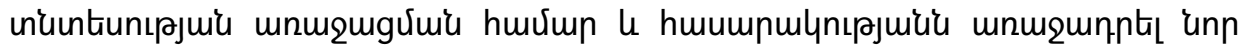

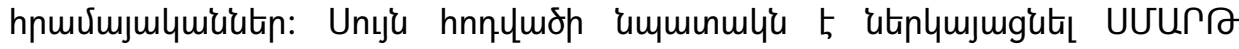

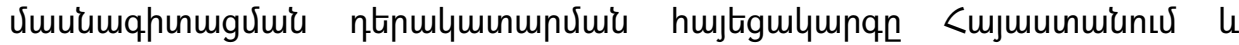

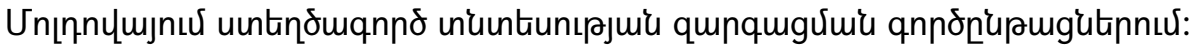

РОБЕРТ ХАЧАТРЯН, ЕЛЕНА СИМЧУК - СМАРТ СПЕЦИАЛИЗАЦИЯ КАК СТИМУЛ РАЗВИТИЯ КРЕАТИВНОЙ ЭКОНОМИКИ В АРМЕНИИ И В МОЛДОВЕ

Ключевые слова: СМАРТ специализация, креативная экономика, креативные активы, образовательные инновации, образовательные программы

Экономические системы претерпели ряд структурных изменений, обусловленные научно-исследовательскими достижениями, инновационными технологиями и творческими решениями актуальных проблем 21-го века. С появлением беспрецедентных изменений экономических моделей и финансовых систем, государственная политика, направленная на специализацию СМАРТ, и инвестиции в процессе создания креативных активов послужили основой для создания креативной экономики. Цель данной статьи - концептуализация роли СМАРТ специализации в процессе развития креативной экономики в Армении и в Молдове.

Utplumumgltt 5' 04.03.2021

9pmunuctti t5' 16.03.2021 